\title{
Conexão Letras
}

ENTREVISTA $^{1}$ COM IRÈNE FENOGLIO ${ }^{2}$

Gabriela Barboza ${ }^{3}$

Heloisa Monteiro Rosário ${ }^{4}$

Valdir do Nascimento Flores ${ }^{5}$

\section{Gabriela Barboza (GB), Heloisa Monteiro Rosário (HR) e Valdir do Nascimento Flores}

(VF): A senhora poderia contar um pouco de sua trajetória profissional até chegar aos estudos dos manuscritos de linguistas, tais como Saussure e Benveniste?

Irène Fenoglio (IF): Nem sempre é simples explicitar, para os outros, aquilo que nos parece evidente, ainda mais porque as coisas mudaram bastante hoje em dia, em comparação ao que estava acontecendo em minha geração. Hoje, apesar de clamarmos pela necessidade da multidisciplinaridade, se você não é hiperespecializado, você não é levado a sério. Assim, minha trajetória é diversa e não linear.

Após prestar vestibular para a área literária, estudei, ao mesmo tempo, literatura e filosofia. Uma vez obtidos os dois diplomas, fiz um mestrado (isso corresponde a um Master

\footnotetext{
${ }^{1}$ A entrevista, cujas perguntas foram formuladas em conjunto pelos entrevistadores, foi realizada por escrito, via e-mail; as respostas foram recebidas no dia 17 de setembro de 2020. Tradução de Daniel Costa da Silva. Graduado em Letras/Tradução pela Universidade Federal do Rio Grande do Sul (UFRGS). Mestre em Letras Estudos da Linguagem pela Universidade Federal do Rio Grande do Sul. Atualmente é doutorando em Letras Estudos da Linguagem pela UFRGS. E-mail: utopiste@hotmail.com.

${ }^{2}$ Irène Fenoglio é linguista, diretora de pesquisas no Instituto de Textos e Manuscritos Modernos (ITEM), do Centro Nacional de Pesquisas Científicas (CNRS), na École Normale Supérieure (ENS) da França. Sua pesquisa tem como foco a genética textual e a teoria da linguagem de Émile Benveniste. Publicou, entre outros: Une auto-graphie du tragique; les manuscrits de Les Faits et de L'avenir dure longtemps de Louis Althusser (2007), L'écriture et le souci de la langue (2007); com Pascal Quignard, Sur le désir de se jeter à l'eau (2011). Estabeleceu, com Jean-Claude Coquet, uma edição de manuscritos de Émile Benveniste: Dernières leçons: Collège de France 1968-1969 (2012); três livros em homenagem ao linguista: Autour d'Émile Benveniste (2016), Émile Benveniste, 50 ans après les Problèmes de linguistique générale (2019) e Émile Benveniste : a gênese de um pensamento (2019) - publicado somente em português.

${ }^{3}$ Doutora em Letras pela Universidade Federal do Rio Grande do Sul (UFRGS). Atualmente, é professora de produção de texto e de língua espanhola da Universidade Federal do Rio Grande (FURG).

${ }^{4}$ Doutora em Letras pela Universidade Federal do Rio Grande do Sul (UFRGS). Atualmente, é tradutora e professora de língua francesa dos cursos de graduação em Letras da Universidade Federal do Rio Grande do Sul e professora e orientadora na linha Análises Textuais, Discursivas e Enunciativas do Programa de Pós-Graduação em Letras da mesma Universidade.

${ }^{5}$ Doutor em Letras pela Pontifícia Universidade Católica do Rio Grande do Sul (PUCRS). Atualmente, é professor titular em Língua Portuguesa dos cursos de graduação em Letras da Universidade Federal do Rio Grande do Sul (UFRGS) e professor e orientador na linha Análises Textuais, Discursivas e Enunciativas do Programa de Pós-Graduação em Letras da mesma Universidade. É bolsista Produtividade em Pesquisa do CNPq (1D).
} 
1 atualmente) de filosofia com Emmanuel Levinas, sobre um tema metafísico. Passei a estudar Husserl, Heidegger e Sartre para me questionar se era possível fazer a pergunta de Leibniz: "Por que há algo em vez de nada?".

Eu saí desse trabalho com a impressão de que a filosofia estava me roubando o mundo; eu tinha um sentimento profundo de que eu devia deixar a abstração para atingir o mundo sensível. Comecei, então, a aprender árabe e hebraico. $\mathrm{O}$ fato de haver diferentes sistemas para dizer o mundo me fascinava. Aprender essas duas línguas, muito próximas, estava ficando difícil e me dediquei exclusivamente ao árabe. Quando terminei o curso de árabe, entrei em linguística: o fascínio experimentado pelo fato de que um sistema tão diferente daquele de nossas línguas latinas também permitia falar e escrever me reconciliava com o mundo sensível: o da voz, o da pronúncia; de repente, entendi o que era um fonema, ou seja, eu estava experimentando a própria materialidade da linguagem. Ao fazer isso, eu queria entender. E entender como a linguagem funciona é fazer linguística.

Após uma primeira tese (na época, tínhamos que passar por duas teses, a tese de terceiro ciclo e a tese de estado) sobre um autor egípcio de língua francesa, Albert Cossery, em que analisei como "seu francês", se não era um decalque, pelo menos imitava sotaques árabes, eu me dediquei à linguística. Depois de vários cargos de professora no Marrocos, no Egito e em Paris, fui recrutada como pesquisadora no CNRS.

Devorando os Problemas de Linguística Geral de Benveniste, trabalhei em questões sociolinguísticas enquanto me questionava sobre os fundamentos da enunciação e as formas de entender seus mecanismos.

Um dia, enquanto preparava um curso sobre enunciação, decidi usar, com os alunos, uma página de um rascunho de Louis Althusser que tinha acabado de ser publicada em sua autobiografia $O$ futuro dura muito tempo. As potencialidades de compreensão que os manuscritos representavam, com as hesitações materializadas por várias operações de escrita, me pareciam extraordinárias.

De início, trabalhei linguisticamente com qualquer manuscrito; depois, percebi que, se eu trabalhasse com manuscritos de linguistas, eu poderia entender melhor como as teorias se elaboravam. Os manuscritos de Saussure já haviam sido amplamente explorados; porém, mais com o propósito de edição do que para entender o processo de escrita. Benveniste era meu mentor linguístico, assim, eu queria trabalhar com seus manuscritos, que procurei por um longo tempo enquanto eles estavam tranquilamente na Biblioteca Nacional da França, mas escondidos e adormecidos, por 30 anos, no departamento orientalista dos manuscritos. 
Juntamente com alguns colegas e estudantes (incluindo muitos brasileiros!), nós nos engajamos na descoberta (em todos os sentidos do termo) do conjunto dos arquivos. Isso deu origem a estudos muito bonitos e não menos belas publicações, todas traduzidas, acredito, em português, no Brasil. E agradeço infinitamente aos pesquisadores e estudantes brasileiros que contribuíram para esse desenvolvimento; não sei se eles estão cientes da imensa importância de seu trabalho.

GB, HR e VF: Historicamente, os trabalhos de genética textual têm-se dedicado a estudar o processo de elaboração da escrita de autores do campo da literatura. Considerando o campo da linguística, como estudos dessa natureza - a exemplo daqueles que constam em Émile Benveniste: a gênese de um pensamento (FENOGLIO, 2019), de sua autoria, recentemente publicado no Brasil - podem, de modo geral, auxiliar no entendimento da elaboração de pensamentos teóricos e, em especial, na reelaboração de métodos e objetos da ciência linguística?

IF: Sim, a genética textual se fundou na análise de rascunhos de escritores. Tratava-se, então, por um lado, de afirmar que a escrita é processual e, por outro lado, compreender e descrever esse processo trazido à tona. Nesse contexto, a equipe "Manuscritos e Linguística" do ITEM aplicava a linguística da enunciação em arquivos literários. Essa equipe não apenas abriu o caminho com, por exemplo, um arquivo misto como "Flaubert e a frase", de Barthes, mas também, e acima de tudo, mostrou que os parâmetros de análise só poderiam ser refinados pelo estudo de vários corpora, de diversos autores.

O primeiro ponto é o que faz o essencial da herança para o estudo dos manuscritos linguísticos. Analisar linguisticamente a textualidade dos rascunhos em seu futuro texto e a discursividade sendo construída através das quatro operações (acréscimo, supressão, substituição, deslocamento) constitutivas de qualquer movimento de escrita, com a avaliação daquilo que elas trazem como restrições de língua, permite o uso do microscópio e oferece, portanto, uma visão aguçada que o especialista do autor, ocupado que está de uma visão telescópica variável de uma obra, nem sequer está, necessariamente, a ponto de identificar.

Os arquivos de Saussure foram os primeiros trabalhos de linguistas a ter sido objeto de uma empreitada global de investigação e de estudo graças ao Círculo Ferdinand de Saussure. O objetivo era claro: Saussure, ao ser considerado, por um lado, como o "fundador" da linguística e ao ter publicado muito pouco, era necessário abrir seus manuscritos para tornar 
público seu conteúdo, uma vez que os manuscritos eram, então, apenas uma ferramenta para apresentar a leitura de uma teoria sem, por isso, ter interesse neles mesmos. O foco essencialmente editorial favoreceu uma abordagem filológica, uma abordagem que, desde o início dessa empreitada, foi a abordagem predominante. A abordagem genética, ausente no início - já que, em comparação com o conjunto dos manuscritos, poucos textos finais, $a$ fortiori publicados, são detectáveis - se desenvolveu hoje graças ao que poderíamos chamar de "efeito Benveniste". De fato, trabalhar no acervo Benveniste envolvia aprender sobre a maneira como os saussurianos trabalhavam. Em contrapartida, alguns saussurianos logo se interessaram pelos trabalhos que diziam respeito à abertura desse "novo" acervo linguístico; troca e colaboração vieram na sequência e, atualmente, pesquisas genéticas precisas estão sendo conduzidas.

Além desses legados diretos, é preciso acrescentar preocupações contemporâneas de nossas pesquisas: no início dos anos 2000, muitos trabalhos se concentraram na identificação, em escritos linguísticos (publicados), das marcas linguísticas específicas de seu funcionamento. Embora esses trabalhos não se voltem para as fontes manuscritas ou processuais dos textos que estudam, suas análises foram valiosas para nosso campo e os resultados alcançados sobre as formas linguísticas envolvidas são elementos que conseguimos levar em conta. A linguística, ao observar a escrita linguística produzida, só pode estimular a busca das características da escrita linguística em produção.

É possível apontar duas abordagens, sempre conjuntas, que acompanham qualquer observação de manuscritos de linguistas.

A historiografia linguística está necessariamente presente, para não dizer imposta. Saber, por exemplo, que Meillet é o herdeiro de Saussure e o mestre de Benveniste, que Benveniste é o herdeiro de Saussure, via Bréal e Meillet, que Meillet assume a sequência de Bréal no Collège de France, etc, será um conhecimento prévio para qualquer leitura dos manuscritos. É evidente que todo manuscrito, por um lado, deve ser situado muito precisamente na história das linguísticas, mas, por outro lado, todo manuscrito contém o potencial de nos informar historicamente sobre a história das ideias linguísticas.

Além disso, o uso combinado do telescópio e do microscópio, conforme a expressão de Carlo Ginzburg, se mostra ainda pertinente. Isso implica constantemente uma escala de observação variável e, sobretudo, a concomitância de um ponto focal e de um conjunto com múltiplas dimensões no qual esse ponto é tomado. Daí a importância do detalhe na genética, na linguística isso é a própria evidência. Rasuras "minúsculas" em manuscritos às vezes 
mudam a situação quase literalmente. É possível que essa circunstância de trabalho possa ser encontrada para qualquer genética das ciências humanas, e que isso constitua sua especificidade em relação ao campo literário. Não que este último não recorra a essa variabilidade de escala, mas, nas ciências humanas, não se pode compreender a construção de um conceito sem esse teste constante e elástico. Por exemplo, uma inovação terminológica só poderá ser confirmada se, de antemão, foi visitado, e em todos os sentidos, o espaço em que aquilo que observamos se inscreve.

A escrita linguística tem sido objeto de diversos trabalhos (análises de discurso, estudos de gêneros, trabalhos de terminologia, gênese de noções a partir de um conjunto de textos publicados), mas nenhum desses estudos se concentrou, a fim de compreender a escrita científica e a conceituação das noções, no aspecto genético e processual do discurso teórico no momento em que está se textualizando, visível em manuscritos de linguistas. Como um autor linguista leva isso em conta para pensar seu objeto, elaborar uma noção, formular seu discurso? A questão pode parecer banal, aos olhos da prática genética. No entanto, ela é extremamente complexa e nova no que tange ao campo linguístico.

Duas ferramentas de análise vêm desarticular, diretamente, sem qualquer intermediário, seu objeto. A prática genética decompõe as camadas instanciadas na hora da escrita e cujos manuscritos guardam o rastro; a sagacidade linguística delineia os enunciados compactados pelas rasuras e decompõe os elementos das frases. Sem essa dupla escavação, o permafrost, compacto, do texto publicado, trabalhado, já comentado, não mostra nada da forma como foi gerado e pode permanecer em silêncio para sempre sobre o essencial do que o constituiu. Porém, a dificuldade em si é dupla: o texto permafrost é um texto linguístico do qual queremos ver emergir a consistência linguística. Surge, então, a seguinte questão: analisar linguisticamente os traços verbais da elaboração em curso de produção de um texto com o propósito de teorização linguística teria outro interesse além do genético? Em outras palavras, o exame linguístico da enunciação processual, mas titubeante, de um texto linguístico seria heurístico, inclusive para o conhecimento linguístico? Seria preciso ler os manuscritos para compreender as teorias?

Tentarei mostrar que a leitura dos manuscritos - que preparam, refletem e ensaiam a escrita de um discurso linguístico - permite não somente desvendar um processo de gênese escritural, mas também um processo de nascimento conceitual, de invenção teórica, pois mostrar os manuscritos é mostrar o texto sendo escrito, se fabricando, se materializando em sua própria matéria, que é a do discurso. 
A visibilidade da elaboração conceitual (o surgimento das palavras e frases que gradualmente constituem o discurso através de sucessivas rasuras) teria a capacidade de mudar a compreensão das noções e conceitos oferecidos no discurso teórico publicado?

Acho que posso afirmar que a abertura dos manuscritos de linguistas é necessária para a linguística teórica e histórica. O que se encontra aí permite compreender a problemática última da teoria trabalhada: aumentar o conhecimento, ampliá-lo, torná-lo heurístico. A relação do manuscrito linguístico com o texto publicado é uma relação entre descoberta e transmissão, cujo prolongamento e desenvolvimento é de mesma natureza: o aumento crítico do conhecimento.

Seria preciso ler os manuscritos para compreender as teorias? Sim; e aí se encontra a diferença em relação aos textos literários. Os manuscritos literários não estão no mesmo patamar da obra publicada. Necessária para compreender o processo de escrita, a questão genética é totalmente separada do objetivo primário da literatura e de seu efeito direto. A relação do manuscrito literário com o texto publicado é uma relação entre o processo de modelagem e de formatação, a inscrição do estilo e a proposta de um texto fechado, que se basta a si mesmo; há uma autossuficiência do texto literário por sua função essencial - a leitura - enquanto a função essencial do texto teórico é a compreensão e o uso para um progresso sempre em andamento. Procurar a gênese de uma noção teórica na obra publicada requer, potencialmente, procurar sua gênese nos manuscritos.

Isso significa que o manuscrito linguístico é mais rico? Óbvio que não, mas há uma diferença de status: o discurso linguístico não tem o mesmo status do texto literário. Textos literários se sustentam sozinhos em seus textos impressos. Buscar compreender seu processo de gênese é um gesto diferente de ler.

Os textos linguísticos devem se sustentar em seus textos impressos para funcionar. Pode ser suficiente lê-los para avançar no conhecimento, mas, se alguém quiser entrar na abordagem teórica em si, é preciso abrir os manuscritos dos quais são provenientes; essa abertura se inscreve na própria abordagem de compreensão e de leitura teórica, na própria abordagem de aumento do conhecimento. Se isso nem sempre é necessário, é, pelo menos, sempre pertinente e suscetível de amplificar ou de corrigir uma leitura que jamais se basta a si mesma.

GB, HR e VF: Como a senhora tem avaliado a recepção das traduções das Últimas aulas no mundo e seus efeitos em relação às ideias de Benveniste? 
IF: O sucesso das Últimas Aulas de Émile Benveniste foi bem surpreendente. Durante muito tempo, as publicações linguísticas não eram mais mencionadas em jornais e na mídia. No entanto, com a publicação das Últimas Aulas, houve um dossiê no Le monde ${ }^{6}$, uma página no Cahier livres do jornal Libération ${ }^{7}$, um programa na rádio France-Culture ${ }^{8}$, um artigo na Quinzaine littéraire ${ }^{9}$, entre outros. Foi uma bela surpresa a atenção dada à linguística e mais a Benveniste. Por que esse sucesso? Não saberia dizer.

Talvez, por um lado, entre aqueles que escreveram sobre essa obra, havia uma nostalgia dessa época de um pensamento vivo e atento que caracterizava os anos 70 . Por outro lado, a obra acompanhava a biografia de Jacques Redard, o prefácio e o posfácio de Kristeva e de Todorov que o haviam conhecido. Finalmente, por outro lado ainda - e espero que este seja o mais importante - houve esse interesse pelas aulas sobre a escrita. E é verdade que este livro é muito importante por isso. As aulas sobre a escrita representam uma reflexão de uma profundidade vertiginosa sobre as próprias fontes daquilo que constitui os próprios fundamentos de nossa civilização humana. Acho que isso foi percebido. Há ainda o fato de que, para os especialistas de Benveniste, faltava uma teoria da escrita entre as muitas áreas tratadas pelo linguista: ela estava lá, nessas magníficas aulas, e diretamente relacionada aos problemas do sentido e da significação.

Como resultado, houve um entusiasmo em relação à tradução dessa obra. Os brasileiros foram os primeiros a querer traduzi-la, depois os argentinos, os suíços, os alemães; acabou de ser publicada a tradução inglesa e logo virá a tradução tcheca. Uma tradução japonesa está prevista.

Qualquer empreitada de tradução, seja ela qual for, é um sinal de interesse, especialmente no campo linguístico, que ainda é um campo menos “popular". Que os tradutores consigam convencer os editores indica necessariamente a antecipação de uma abertura de espírito.

\footnotetext{
$6 \quad \mathrm{O}$ dossiê a que se refere a entrevistada está disponível em https://www.lemonde.fr/livres/article/2012/04/19/des-concepts-et-des-hommes_1687462_3260.html; https://www.lemonde.fr/livres/article/2012/04/19/le-linguiste-dont-la-vie-fut-un-roman_1687460_3260.html e https://www.lemonde.fr/livres/article/2012/04/19/il-me-lisait-le-rigveda-directement-en-sanskrit-dans-le-texte_1 687463_3260.html.

${ }^{7}$ Disponível em https://next.liberation.fr/livres/2012/04/25/delier-la-langue_814343.

$8 \quad$ Disponível em http://www.franceculture.fr/emission-le-journal-de-la-philosophie-emile-benveniste-dernieres-lecons-2012-05-07

${ }^{9}$ Disponível em https://www.nouvelle-quinzaine-litteraire.fr/mode-lecture/benveniste-fascinant-et-multiple-143. 282 - Conexão Letras, Porto Alegre, v. 16, n. 25, p. 276-292, jan-jun. 2021. 
Os pesquisadores linguistas responderam ao entusiasmo dos tradutores e graças a toda essa cadeia de trabalho (busca por manuscritos, sua leitura e análise, sua edição e, em seguida, suas traduções, e depois a edição de suas traduções), Benveniste foi lido, relido e os professores tiveram um novo meio para fazer os alunos descobrirem uma teoria interessante e ainda mais interessante, pois se posiciona contra a corrente de estudos hiper especializados da atualidade e contra uma visão da linguística muitas vezes reduzida a palavras de ordem modeladoras, cada vez mais distante de uma visão global do humano.

Gostaria de aproveitar esta pergunta para dizer isso. Um mundo intelectual, acadêmico ou não, não pode funcionar sem que grandes esforços sejam empreendidos na tradução. Estamos cada vez mais sendo forçados a falar uma única língua, o inglês, que nos empobrece, assim como ela própria se empobrece por ser mal escrita, globishizada. Ganharíamos tanto em refinamento, em conhecimento dos outros, caso nossas sociedades dedicassem partes importantes do orçamento para as traduções. E no campo da linguística, a tradução é tão heurística, para entender fenômenos difíceis, quanto necessária. Sobre esse tema da tradução, é uma felicidade poder ler o texto de Benveniste "A tradução, a língua e a inteligência" publicado na abertura do volume Autour d'Émile Benveniste.

Então, sim, um agradecimento aos tradutores!

GB, HR e VF: Como as recentes publicações de manuscritos até então inéditos de Benveniste podem redimensionar o entendimento da teoria da linguagem do autor, excessivamente apresentada, ainda hoje, apenas ligada aos estudos da enunciação?

IF: As recentes publicações sobre Benveniste reconduziram um olhar voltado para o conjunto dos trabalhos do linguista.

Era um erro considerá-lo preocupado apenas com as questões de enunciação. Pois sua teoria da enunciação está diretamente relacionada com sua compreensão da linguagem em geral. E essa compreensão é sustentada por um trabalho de longo prazo - jamais abandonado - de filólogo e de gramático (no sentido de "gramática comparada"), ou seja, em que se misturam a história da linguística, a adoção crítica da linguística saussuriana, a historiografia linguística e a elaboração de uma linguística geral. Podemos separar as questões, reunir artigos de diferentes campos, mas o objetivo de Benveniste sempre foi desenvolver uma linguística geral, capaz de levar em conta todos os aspectos da linguagem: desde as 
especificidades de diferentes sistemas de língua, até questões de sociolinguística, bem como os traços mais particulares da língua em discurso, ou seja, na enunciação.

Muitos linguistas só queriam ver em Benveniste o teórico da enunciação, esquecendo que esse aspecto não pode ser separado, nele, de suas outras pesquisas sobre línguas indo-europeias, assim como sobre outros conjuntos de línguas. Nesse sentido, o último volume publicado (Émile Benveniste, 50 ans après les Problèmes de linguistique générale) é muito importante, pois as diferentes contribuições da primeira parte mostram isso.

GB, HR e VF: Considerando a publicação das Últimas aulas, como a senhora avalia a "descoberta" de um pensamento em desenvolvimento sobre a escrita, assim como a "redescoberta" de conceitos que figuram nos manuscritos mais recentemente publicados, como, por exemplo, os pares designar-significar, semiótico-semântico e a noção de interpretância?

IF: A descoberta dos manuscritos relativos à teoria da escrita foi, para mim, extraordinária. Por um lado, evidentemente que o tema da escrita é um tema constante de trabalho para mim, como geneticista do texto, e por outro lado, era uma questão que Benveniste havia mencionado em alguns artigos e tinha deixado sem solução. Devo dizer que foram esses manuscritos sobre a escrita que me convenceram a publicar os últimos cursos no Collège de France e, para isso, eu busquei os ouvintes que haviam presenciado esses cursos.

Nessas aulas sobre a escrita, há uma reutilização do par conceitual “designar/significar". Seria isso uma redescoberta? Não sei. Se lermos Benveniste no conjunto de suas obras e não apenas os Problemas de Linguística Geral, esse duplo conceito está muito presente por se tratar de um operador de sua linguística comparada. De qualquer forma, nessas aulas sobre escrita, ele mostra novamente a qualidade heurística disso, além de sua prática metodológica. Em relação a semiótico/semântico, a "redescoberta" ocorre apenas para os leitores das Últimas Aulas que não teriam lido ou esquecido o artigo "Semiologia da língua" no volume 2 de Problemas de Linguística Geral. Jean-Claude Coquet e eu explicamos bem, na introdução das Últimas Aulas, que os dois anos, 1968 e 1969 - que precedem o longo período de imobilidade de Émile Benveniste, isto é, seu longo silêncio devido à afasia, antes de sua morte em 1976 - são marcados por uma intensa atividade voltada, em particular, para a elaboração do par "semiótico/semântico". Diferentes dimensões e posturas de sua atividade científica estão, assim, em ação: o teórico escreve e publica "Semiologia da Língua", artigo 
no qual ele explicita seu conceito central de "semiótico/semântico"; o pesquisador busca as elucidações teóricas de sua concepção do sentido na linguagem e as exibe no Primeiro Simpósio de Semiótica que acontece em Varsóvia; por fim, o professor transmite, em seus cursos no Collège de France, seus conhecimentos de erudito, os problemas teóricos do pesquisador sobre os quais ele desenvolve áreas cujos resultados estão sendo estabilizados no artigo.

Ocorre o mesmo em relação à noção de interpretância. Essa noção está perfeitamente desenvolvida no artigo "Semiologia da língua".

Parece-me, portanto, que estamos lidando menos com uma redescoberta dessas noções do que com uma redescoberta de Benveniste. Graças às Últimas Aulas e ao sucesso midiático que veio na sequência, Benveniste reaparecia na circulação dos conhecimentos. É preciso dizer que foi, ao mesmo tempo, graças à equipe "Linguística" do ITEM, que se dedicou a ele e, no plano internacional, graças às traduções (especialmente brasileiras).

GB, HR e VF: Os anos 1960 são marcados, na França, por uma discussão em torno da semiologia. Benveniste participa ativamente desse debate da época: em 1968, faz a conferência de abertura do Primeiro Simpósio Internacional de Semiótica; já em 1969, torna-se o primeiro presidente da Associação Internacional de Semiótica, da qual é um dos fundadores, assim como aceita presidir o Círculo de Semiótica de Paris. Nesse mesmo período, ainda podemos apontar suas aulas sobre semiologia no Collège de France e a publicação do artigo "Semiologia da língua" na revista Semiotica. Contudo, Roland Barthes, grande referência dos estudos em semiologia na França, em sua resenha do segundo volume dos Problemas de Linguística Geral, de 1974, não retoma nem discute a reflexão apresentada pelo linguista em "Semiologia da língua", salientando apenas a grande contribuição do livro para a enunciação. Ainda que muito respeitosa e elogiosa, a resenha de Barthes não teria contribuído para um "encerramento" do pensamento de Benveniste no campo enunciativo, silenciando, de certo modo, outros vieses de sua reflexão, como o viés semiológico? Como a senhora caracterizaria o engajamento e o papel de Benveniste nesse debate semiológico dos anos 1960, assim como seu diálogo com outros pensadores do campo?

IF: Sim, certamente, Roland Barthes, em sua admiração por Benveniste, colaborou para orientar sua recepção na direção, digamos, do "literário", onde, é claro, a noção de enunciação muito contribuiu. A orientação de Benveniste na direção da literatura continua até hoje. Mas 
direi que isso não é culpa de Barthes, nem de Benveniste. O que aconteceu foi que os linguistas têm cada vez mais se voltado para a linguística chomskyana e suas transformações, o que é incompatível com uma linguística tal como Benveniste a concebe. Para ir direto ao ponto, Benveniste diz que sem a linguagem não há pensamento, ou seja, é a linguagem que estrutura o pensamento; para Chomsky, o pensamento existe previamente, ou seja, a língua só está lá para traduzir o pensamento de acordo com processos previamente codificados.

A especialização excessiva e a predominância hoje em dia de estudos "cognitivos" que limitam a parte da linguagem a uma parte instrumental e não fundamental continuam essa visão.

Não tenho muito a dizer sobre a posição de Benveniste nesse debate, pois sua ponderação é importante. Ele continuou a trabalhar incansavelmente em toda a extensão dos campos dos quais fazia parte; essa era sua arma. Vimos, a partir das Últimas Aulas, mas também a partir das notas sobre o discurso poético, que não são notas sobre Baudelaire como se quis dar a entender, para continuar o colocando na literatura -, mas que constituem uma profunda e complexa reflexão sobre esse tipo particular de discurso, que é o discurso poético. Ele se indaga, na condição de linguista, sobre uma forma de discurso específica e não sobre um autor poeta.

O que deve ser percebido é que foi durante esses anos - os anos sessenta, quando os modelos linguísticos dominantes (estruturalismo, gramática generativa) estavam, principalmente, ou, até mesmo, exclusivamente, interessados na descrição da língua como estrutura - que Benveniste desenvolveu e publicou sua conceituação sobre "semiótico e semântico". Nisso, ele se distancia do que pode ser genericamente chamado de "semiologia", a ciência dos signos. Como sempre, Benveniste não entra em polêmica (embora ele afirme suas posições em relação às de Bloomfield ou de Chomsky, por exemplo, em seus artigos); ao contrário, ele analisa e argumenta. Ele se apega estritamente a seu campo linguístico e mostra como concebe essa dupla dimensão inerente ao exercício da linguagem, a dupla dimensão semiótico (que diz respeito ao sistema da língua) e semântico (que diz respeito à enunciação: a língua em ato oral ou escrito).

Foi em 1966, por ocasião do $13^{\circ}$ Congresso das Sociedades de Filosofia de Língua Francesa, que Émile Benveniste propôs, pela primeira vez, o par de termos "semiótico" e "semântico". Ele próprio afirma que a elaboração desse duplo conceito é "a finalização da análise apresentada anteriormente sob o título de "Os Níveis da Análise Linguística" (BENVENISTE, 1989, p. 64, nota 28). De fato, nesse artigo de 1964, se os próprios termos de 
semiótico e semântico não figuravam, a problemática de duas "linguísticas" estava bem presente: “[...] se deixa, com a frase, o domínio da língua como sistema de signos e se entra num outro universo, o da língua como instrumento de comunicação, cuja expressão é o discurso" (BENVENISTE, 1995, p. 139).

Retomando essa análise nos anos de 1968 e 1969, ele especifica as noções de "semiótico" e "semântico" e as conceitualiza no artigo "Semiologia da língua", bem como em sua apresentação no primeiro Simpósio de Semiótica e em seu curso no Collège de France.

Então, como caracterizar sua posição nesse debate? Através do trabalho e da transmissão de suas pesquisas teóricas.

GB, HR e VF: A partir dos anos 1970, muitos autores retomaram a reflexão de Benveniste em "Semiologia da língua", procurando desenvolver, cada um a seu modo, sobretudo o final programático do artigo que propõe a noção de metassemântica. Em que medida a publicação dos manuscritos de suas últimas aulas no Collège de France redimensiona o entendimento da reflexão semiológica de Benveniste para além da metassemântica?

IF: É possível, de fato, se perguntar sobre o que Benveniste quis dizer com o que está colocado bem no final de seu artigo "Semiologia da língua":

\footnotetext{
Em conclusão, é necessário ultrapassar a noção saussuriana do signo como princípio único [...]. Esta ultrapassagem far-se-á por duas vias:

- na análise intralinguística, pela abertura de uma nova dimensão de significância, a do discurso, que denominamos semântica [...];

- na análise translinguística dos textos, das obras, pela elaboração de uma metassemântica que se construirá sobre a semântica da enunciação.

Esta será uma semiologia de "segunda geração", cujos instrumentos e o método poderão também concorrer para o desenvolvimento das outras ramificações da semiologia geral. (BENVENISTE, 1989, p. 67).
}

É possível imaginar que, neste trecho, ele está pensando nas análises de Barthes que, não nos esqueçamos, diz praticar a semiologia. Ora, Barthes faz análises literárias baseadas em conhecimentos linguísticos (especialmente, os de Benveniste, de quem ele "gosta"), mas não permanece no nível do intralinguístico: ele opera suas análises em "textos", "obras" e, portanto, se situa em uma "segunda geração" enunciativa. Ele trabalha metalinguísticamente no nível não $\underline{d o}$ discurso (instância linguística), mas $\underline{d o s}$ discursos, ou seja, dos textos, quer se trate de literatura ou de outras manifestações sociais.

Imagino as coisas dessa forma e acredito que esta última observação programática não modifica em nada a reflexão linguística de Benveniste sobre as duas instâncias intralinguísticas: o semiótico e o semântico. Essas duas instâncias, não importa o que se faça, 
permanecem inerentes ao funcionamento da linguagem. A única coisa possível é se colocar em outro ponto de vista, mais macro e que analisa os textos constituídos.

GB, HR e VF: A publicação das Últimas aulas não apenas propicia o conhecimento e a divulgação de manuscritos inéditos do linguista, mas também informa sobre a trajetória pessoal e profissional de Benveniste, trazendo diferentes contornos (o do pesquisador, do erudito e do professor) para a composição da figura desse importante teórico da linguagem. Outras publicações, como Autour d'Émile Benveniste e Émile Benveniste, 50 ans après les Problèmes de linguistique générale, também abordam a vida e a recepção da obra do autor. Como a articulação entre vida, obra e teoria pode contribuir para uma compreensão mais ampla do pensamento teórico de um autor como Benveniste, por exemplo?

IF: Esta é uma pergunta muito difícil e delicada.

Certamente, há uma conexão entre a vida e a obra de um linguista. Mas quanto a determiná-la, explicá-la, já é outra questão.

A biografia de Redard (publicada em As Últimas Aulas) nos permite compreender sua formação e, logo, sua trajetória profissional nos inconvenientes da História, tão agitada e cruel, da primeira parte do século XX. Essa biografia permite - sobretudo, àqueles linguistas que só se interessam pelos Problemas de Linguística Geral - compreender o quão vasto e ordenado era seu campo de trabalho. Ele é um linguista por terem lhe ensinado gramática comparada e Saussure; e é apenas porque ele fica arrebatado por línguas indo-europeias e línguas semíticas que ele pode - com pleno conhecimento do funcionamento de vários sistemas linguísticos diferentes - desenvolver toda a parte enunciativa de suas pesquisas. Baseia-se no conhecimento do funcionamento de numerosas línguas para poder - assim como fez Saussure com sua teoria do signo linguístico - "descobrir" o funcionamento do discurso e, assim, reverter a perspectiva saussuriana: não é a linguística que se inscreve na vasta ciência da semiologia; ao contrário, são as diferentes ciências semiológicas que se inscrevem na linguística, pois precisam passar pela língua.

Quanto ao que escrevi em Autour d'Émile Benveniste sobre seu nome, "Le prénom et ses marges", escrevi justamente como resposta a alguns linguistas que me diziam que Benveniste havia se tornado um grande linguista do discurso porque era judeu. Esse tipo de afirmação me parece sempre suspeito. Claro que há certamente uma ligação, já que há sempre 
uma conexão entre sua vida e sua obra, mas qual ligação? Só a pessoa de Émile Benveniste poderia - talvez - revelar isso.

Incomodada com essas observações, eu quis "investigar" e busquei o mais longe possível nos arquivos de sua família. Tomei, como fio condutor, a mudança de nome, de Ezra para Émile, com o intuito de mostrar que Benveniste teve que resolver problemas para adquirir a nacionalidade francesa em uma época difícil; mas, acima de tudo, mostrar que a mudança, de Ezra para Émile, marca a passagem definitiva para o universal do conhecimento, para a linguística. Não se trata de uma conversão; trata-se de uma escolha: como criança, menor de idade, ele teve que ser colocado em uma escola religiosa; já adulto, maior de idade, ele escolhe seu futuro, para não dizer seu destino; e seu futuro é a imersão total e absoluta na busca pelo conhecimento.

Descobrir isso permitiria uma compreensão mais ampla de seu pensamento teórico? Em princípio, não. Isso deve apenas esclarecer aqueles que pensam preconceituosamente que há causas intrínsecas e culturais em nossas escolhas.

Pessoalmente, acho que um indivíduo é certamente marcado pelo ambiente social e familiar em que nasce, mas, uma vez adulto, ele tem a oportunidade de fazer verdadeiras escolhas. As motivações de nossas escolhas são mais subjetivas do que sociais, ou, pelo menos, são tão subjetivas quanto.

GB, HR e VF: Em uma entrevista para a France Culture ${ }^{10}$, a senhora afirma que Benveniste trabalha sobre um paradigma que integra as análises específicas de línguas em uma reflexão sobre a língua e sobre como a linguagem funciona e significa para o homem. De que modo podemos verificar essa indissociabilidade nos textos do linguista?

IF: Lendo os textos. Além disso, já respondi parcialmente esta pergunta ao responder as perguntas anteriores.

Direi, mais especificamente, que isso se percebe apenas relendo os dois volumes dos Problemas de Linguística Geral. Leia realmente apenas os sumários dos dois volumes e os títulos das partes, em seguida, dos artigos, você logo perceberá que eles desenham essa amplitude de campo dos trabalhos de Émile Benveniste. Se você juntar, aos Problemas de

\footnotetext{
${ }^{10}$ Entrevista concedida a Emmanuel Laurentin, em 2016, a propósito do lançamento do livro Autour d'Émile Benveniste. etien-avec-jenny. A referência completa está no final da entrevista.
} 
Linguística Geral, o Vocabulário das Instituições Indo-europeias, você já terá uma ideia profunda do caráter antropológico da linguística benvenistiana.

Muito especificamente, Benveniste quer estabelecer uma linguística geral que permita elucidar tanto o social (a língua) quanto o subjetivo (o discurso). Porém, para estabelecer uma visão ampla e antropológica, é preciso conhecer numerosos sistemas de línguas diferentes. Lembremos do que ele diz em seu Prefácio ao primeiro volume de Problemas de Linguística Geral (1995): “O estudo desses organismos empíricos, históricos, que são as línguas, permanece o único acesso possível à compreensão dos mecanismos gerais e do funcionamento da linguagem".

GB, HR e VF: No livro Émile Benveniste, 50 ans après les Problèmes de linguistique générale, a senhora atribui três dispositivos método-epistemológicos a Benveniste: empiria-teoria, designar-significar, semiótico-semântico. Especificamente sobre o par designar-significar, poderia explicar por que ele deve ser entendido ao mesmo tempo como "uma herança filológica, uma pesquisa etimológica e uma visão antropológica" (D’OTTAVI \& FENOGLIO, 2019, p. 25)?

IF: Nos dois últimos cursos das Últimas Aulas, Benveniste dedica várias páginas a estudos, se não exaustivos, pelo menos muito avançados na maneira como é designado, em diferentes línguas, o ato de ler e o ato de escrever. Sabemos, portanto, o que é "designado". Mas ele insiste e expõe a maneira como essas designações dos mesmos atos significam em diferentes línguas. Esses estudos não estão lá apenas a título de "exemplo"; eles constituem o próprio cerne desse fundamento linguístico que é a distinção, sem separação, do "designar-significar". O que ele diz na abertura dessas análises, na aula 14? "É uma análise de terminologia que é instrutiva se, e na medida em que, podemos distinguir entre a designação e a significação". (BENVENISTE, 2014, p. 167). A terminologia, para Benveniste, não pode ser realizada sem etimologia. Com a etimologia, busca-se reconstituir a evolução e a origem das palavras. Com a filologia, utiliza-se a etimologia para compreender a origem de um texto, comparar versões de textos, etc. Estamos, então, no escrito e apenas no escrito. Percebe-se, portanto, que a etimologia e a filologia constituem uma chave de compreensão da escrita. Benveniste está impregnado dessa formação clássica, que recai sobre seus saberes e metodologias. No entanto, ele traz algo diferente: ele aponta para essa evidência, que é o que faz a complexidade da linguagem: a língua designa, mostra, comunica, mas não apenas isso; ela significa; e, ao 
apontar para isso, Benveniste nos mostra essa evidência. Esta é uma de suas características luminosas: ele se apoia no que parece evidente para todos e mostra o que é essencial e... um essencial complexo. Eis o que é "herança filológica, pesquisa etimológica".

Por que é uma "visão antropológica" enfatizar a necessidade de implementação do par conceitual designar/significar para compreender o linguístico? Bem, pelo fato de que se entendermos que designar é sempre significar, temos uma visão da linguagem como intrínseca ao humano. Não se trata mais apenas de "fazer signo", como um animal pode fazer, nem de obedecer a um programa, como uma máquina pode fazer; trata-se de falar ou de escrever; trata-se de enunciar em uma dimensão singular, ao mesmo tempo, social e individual.

Agradeço por esta pergunta, muito relevante, que me permitiu reexaminar o que eu havia escrito em um impulso imediato.

GB, HR e VF: Em seu texto "Proposition, phrase, énoncé chez Émile Benveniste", a senhora diz: “Benveniste implementará os pares conceituais 'semiótico-semântico' e 'designar-significar' que lhe permitirão fundar a noção de discurso, sem a qual nenhuma teoria do uso da linguagem é possível" (FENOGLIO, 2019, p. 187). Poderia nos falar um pouco mais sobre a relação entre esses pares conceituais e a fundação da noção de discurso?

IF: Bem, eu acho que há um elo muito forte entre designar/significar e semiótico/semântico. O par "semiótico/semântico" é, no plano teórico, o que "designar/significar" é no plano metodológico. Deixe-me explicar.

Benveniste mostra que, se quisermos compreender o funcionamento das línguas e o que as palavras dessa língua carregam, é imperativo fazer linguística comparada e, portanto, caso se compare, é preciso que haja um estável: o estável será o fato de designar. Como se designa "ler", como se designa "escrever" em uma determinada língua, para retomar os exemplos que ele desenvolve nas Últimas aulas.

Porém, ainda que tenhamos a palavra, não temos muito. O que é importante Benveniste mostra isso brilhantemente - é saber de onde vem essa palavra que designa "ler" ou "escrever"; e aí que é necessário voltar à etimologia e aos vários empregos da palavra. Estamos, então, no significar. O que quer dizer que a linguagem significa, como Saussure já havia dito, mas isso também quer dizer que há sempre discurso em torno da palavra. A palavra é o signo em discurso. 
Fica claro aí que o "significar" do primeiro par se assemelha ao "semântico" do segundo par.

\section{Referências}

BARTHES, Roland. "Pourquoi j'aime Benveniste, 2" (1974). In: BARTHES, Roland. Le bruissement de la langue. Essais critiques IV. Paris: Éditions du Seuil, 1984. (Tradução brasileira: BARTHES, Roland. "Por que gosto de Benveniste". In: BARTHES, Roland. $O$ rumor da língua. São Paulo: Editora Brasiliense, 1988. p. 179-183.)

BENVENISTE, Émile. “Avant-propos”. In: BENVENISTE, Émile. Problèmes de linguistique générale, 1. Paris: Éditions Gallimard, 1966. (Tradução brasileira: BENVENISTE, Émile. "Prefácio". In: BENVENISTE, Émile. Problemas de linguística geral I. Campinas: Pontes, 1995.)

BENVENISTE, Émile. "Les niveaux de l'analyse linguistique" (1962/1964). In: BENVENISTE, Émile. Problèmes de linguistique générale, 1. Paris: Éditions Gallimard, 1966, p. 119-131. (Tradução brasileira: BENVENISTE, Émile. "Os níveis da análise linguística" (1962/1964). In: BENVENISTE, Émile. Problemas de linguística geral I. Campinas: Pontes, 1995, p. 127-140.)

BENVENISTE, Émile. "Sémiologie de la langue" (1969). In: BENVENISTE, Émile. Problèmes de linguistique générale, 2. Paris: Éditions Gallimard, 1974, p. 43-66. (Tradução brasileira: BENVENISTE, Émile. "Semiologia da língua" (1969/1974). In: BENVENISTE, Émile. Problemas de linguística geral II. Campinas: Pontes, 1989, p. 43-67.)

Dernières leçons: Collège de France (1968 et 1969) (Orgs. Jean-Claude Coquet e Irène Fenoglio). Paris: EHESS/Gallimard/Seuil, 2012. (Tradução brasileira: BENVENISTE, Émile. Últimas aulas no Collège de France (1968 e 1969) (Orgs. Jean-Claude Coquet e Irène Fenoglio). São Paulo: Editora Unesp, 2014.)

D'OTTAVI, Giuseppe; FENOGLIO, Irène (Orgs.). Émile Benveniste, 50 ans après les Problèmes de linguistique générale. Paris: Éditions Rue d'Ulm/Presses de l'École normale supérieure, 2019.

FENOGLIO, Irène. Actualité des parutions: Entretien avec Jenny Raflik puis avec Irène Fenoglio. Entrevistador: Emmanuel Laurentin. Série Langue Française. Paris: France Culture, 22 fev. 2016. Disponível em : https://www.franceculture.fr/emissions/la-fabrique-de-1-histoire/langue-francaise-14-actualitedes-parutions-entretien-avec-jenny. Acesso em 06 nov. 2020. . Autour d'Émile Benveniste. Paris: Éditions du Seuil, 2016.

Émile Benveniste: a gênese de um pensamento. (Orgs. Valdir do Nascimento Flores, Verónica Galindez Jorge e Heloisa Monteiro Rosário). Brasília: Editora Universidade de Brasília, 2019.

. "Proposition, phrase, énoncé chez Émile Benveniste". In: NEVEU, Franck. Proposition, phrase, énoncé. Londres: ISTE Editions, 2019, p. 183-204.

Recebido em: 15/11/2020; Aceito em: 29/11/2020. 